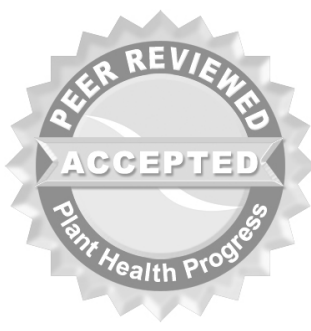

(c) 2013 Plant Management Network.

Accepted for publication 17 June 2013. Published 1 September 2013.

\title{
Identification of a Previously Undescribed Satellite RNA Associated with a Cucumber mosaic virus Subgroup II Strain from Pratia pedunculata in Ohio
}

\author{
John R. Fisher, Ohio Department of Agriculture, Plant Health \\ Diagnostic Laboratory, Plant Health Division, Reynoldsburg, OH 43068 \\ Corresponding author: John R. Fisher. jfisher@agri.ohio.gov
}

Fisher, J. R. 2013. Identification of a previously undescribed satellite RNA associated with a Cucumber mosaic virus subgroup II strain from Pratia pedunculata in Ohio. Online. Plant Health Progress doi:10.1094/PHP-2013-0901-01-BR.

Cucumber mosaic virus (CMV) is the type species of the Cucumovirus genus in the Family Bromoviridae. The virus is distributed worldwide, has a very broad host range infecting over 1000 species in more than 85 plant families, and is transmitted by more than 80 aphid species in 30 genera in a non-persistent manner. The viral genome is positive-sense, single-stranded RNA divided among three segments which encode five proteins. RNAs 1 and 2 encode three proteins with methyl transferase/helicase, replicase, and suppression of RNA silencing functions. The movement protein (MP) gene is expressed directly from the 5 ' half of RNA 3, and the coat protein (CP) gene is expressed from the 3 ' half via a subgenomic RNA, referred to as RNA 4. CMV is divided into two subgroups based on serological and nucleotide sequence relatedness (3). Some isolates are also reported to harbor small satellite (sat) RNAs ranging in size from 330-405 nucleotides (nt) which are dispensible for CMV replication but rely on CMV for replication and on the CMV-CP for encapsidation. The majority of CMV satRNAs attenuate symptoms induced by the helper virus but pathogenic variants can induce chlorosis or necrosis diseases on tobacco or tomato hosts $(4,5,6,7)$.

In the spring of 2012, a landscape sample of Blue Star Creeper (Pratia pedunculata) was submitted to the Ohio Plant Diagnostic Network for a root health issue but it was also showing small, white spots on the leaves. The sample tested positive for CMV and negative for Impatiens necrotic spot virus, Tobacco mosaic virus, and Tomato spotted wilt virus by immunostrips (Agdia Inc., Elkhart, IN). Immunocapture RT using sheep anti-rabbit conjugated magnetic beads incubated with rabbit anti-CMV IgG (Agdia Inc.) followed by PCR with CMV-MP, CP, and satRNA specific primers was done as previously described (2) and all three sets of primers amplified products of expected size (Fig. 1). The amplicons were excised from the gel and cloned into pGEM-T vector as previously described (2). Clones were screened for inserts by PCR using M13 sequencing primers, the plasmid DNA was purified and subsequently sequenced (Plant Microbe Genomics Facility, The Ohio State University), and vector sequences were trimmed from raw sequences (Chromas v. 2.33), assembled, and subjected to pairwise and multiple sequence alignments (Vector NTI Advance 11.5, Invitrogen) as previously described (2). 


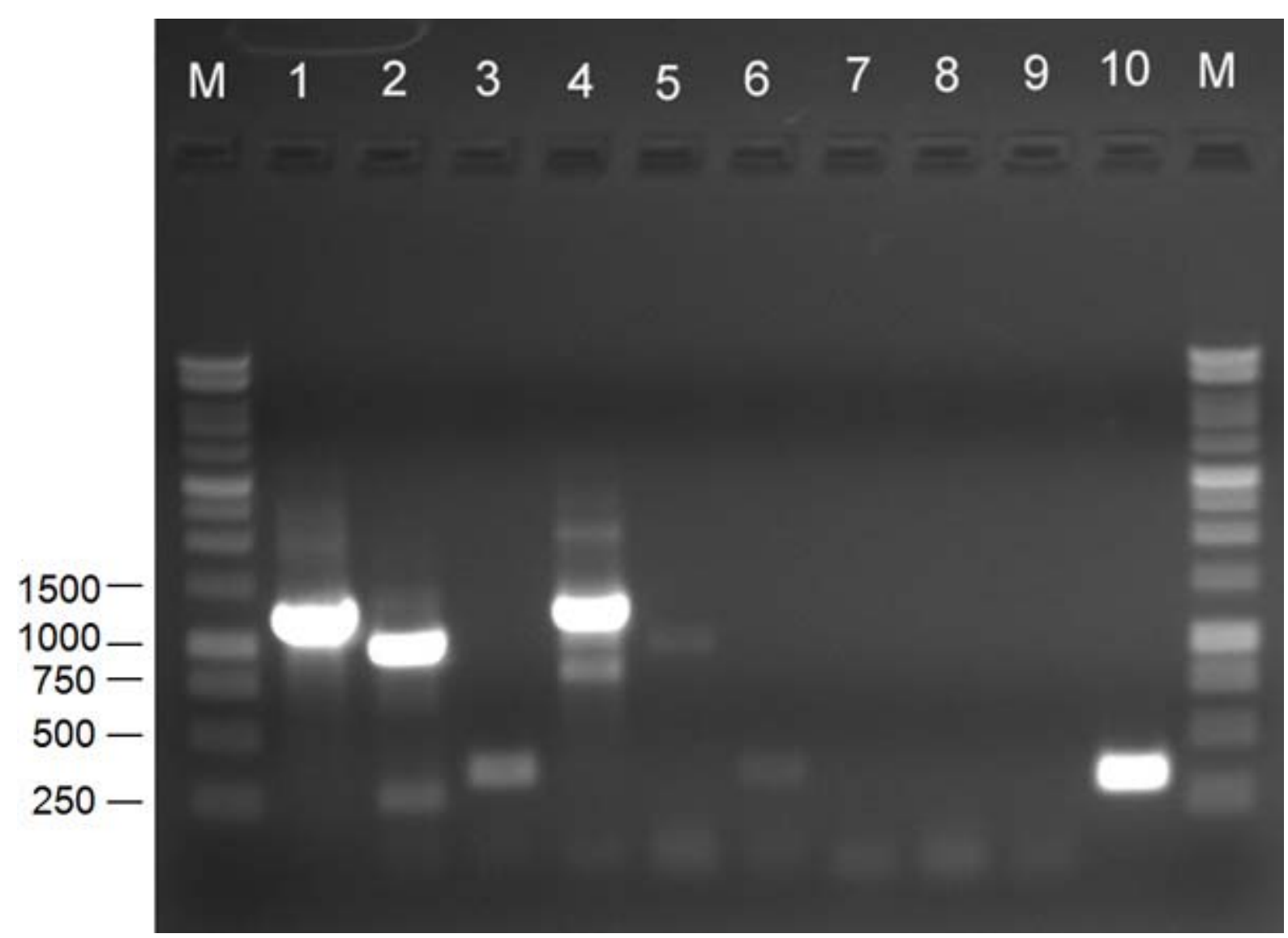

Fig. 1. PCR detection of CMV from CDNAs synthesized from immunocaptured virions from Pratia pedunculata with MPspecific (Lane 1), CP-specific (Lane 2), and satRNA-specific (Lane 3) primers. A CMV isolate from Vinca minor in Nicotiana tabacum 'Glurk' with MP-specific (Lane 4), CP-specific (Lane 5), and satRNA-specific (Lane 6) primers used as a positive IC/RT control. Water negative controls with MP (Lane 7), CP (Lane 8), and satRNA (Lane 9) primers. CMV-Vinca satRNA clone (Lane 10) used as a positive PCR control with satRNA-specific primers. $\mathrm{M}=1 \mathrm{~Kb}$ DNA ladder $(250,500,750,1000$, and 1500 bp markers indicated). Electrophoresis was performed in $0.8 \%$ agarose at 100 volts for 60 min in 1X TAE buffer. Gel was stained with ethidium bromide. MP, CP, and satRNA amplicons are 1194, 974, and $339 \mathrm{nt}$, respectively.

Four MP, five CP, and five satRNA amplicon clones were sequenced and the processed sequences deposited in GenBank (accession numbers KC985197KC985210). All four MP clones were $1194 \mathrm{nt}$, were 99.5-100\% identical to one another, and encompassed the 840 nt MP open reading frame (ORF) which encodes a predicted 279 amino acid (aa) protein. All five CP clones were $974 \mathrm{nt}$, were 99.1-99.8\% identical to one another, and encompassed the $657 \mathrm{nt}$ CP ORF which encodes a predicted 218 aa protein. All five satRNA clones were $339 \mathrm{nt}$ and were 97.1-99.1\% identical to one another. BLASTn searches of the NCBI database using default settings (100\% query coverage) with the MP and CP ORF sequences resulted in matches with $99 \%$ nt identities to CMV subgroup II strains, notably LS (accession number AF127976.1), and two isolates we recently reported from Vinca minor (accession number JF918965.1) and Hosta sp. (accession number JX898519.1) (1,2). BLASTn searches using default settings with the satRNA clone sequences resulted in matches with $93 \%$ nt identity (accession numbers Z75882.1, Z75876.1). The satRNA domains playing roles in the induction of chlorosis and lethal necrosis diseases of tomato have been well characterized $(4,5,6,7)$ and are localized to nt 148-170 and nt 290-309, respectively. When compared to the chlorosis and necrosis domains of necrogenic, ameliorative, and chlorosis inducing satRNAs, the CMV-Pratia satRNA had the most variability in the necrosis domain, which did not resemble the necrosis domains of $\mathrm{D}, \mathrm{WL} 1, \mathrm{WL} 2$, or B1 satRNA (Table 1) and appeared unique. There was less variability in the Pratia satRNA chlorosis domain but it was still not identical to any of the others. Compared to GenBank accession numbers Z75876.1 and Z75882.1 the chlorosis domain differed by a single nt but 
the necrosis domain differed by six nt (Table 1). Phylogenetic analysis of the CMV-Pratia CP and MP ORF and satRNA nt sequences (maximum likelihood phylogeny estimation with 1000 bootstrap replicates; RAxML version 7.4.4; Stamatakis et al. 2008) grouped the helper CMV isolate with subgroup II strains/isolates such as WL, Sn, and LS (Fig. 2). The satRNA grouped to a branch by itself in the same clade as accession numbers Z75882.1 and Z75876.1 (Fig. 2).

Table 1. Comparison of the chlorosis and necrosis domains of CMV-Pratia satRNA to necrogenic (D), ameliorative (WL1), and chlorosis-inducing (WL2, B1) satRNAs, and GenBank accessions having the greatest percent nt identity (Z75876.1, Z75882.1).

\begin{tabular}{|c|c|c|c|}
\hline & & $\begin{array}{c}\text { nt } 148-170 \\
\text { chlorosis domain }\end{array}$ & $\begin{array}{c}\text { nt } 290-309 \\
\text { necrosis domain }\end{array}$ \\
\hline SatRNA & $\begin{array}{l}\text { Accession } \\
\#\end{array}$ & 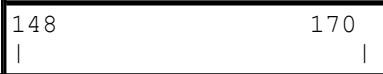 & 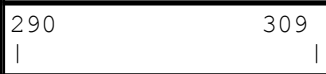 \\
\hline D & M20350.1 & АСТCT-CAGTACTACACTCTCA- & AAGG-CTTAT---GCTATGC \\
\hline WL1 & M30589.1 & АСTCT-CAGCACTACGCGCTCA- & AAGA-CTTAG---GTTATGC \\
\hline WL2 & M16590.1 & GTTCTTCAGCACTACGCACTCAA & AAAACCT-ATAAGGTCATGC \\
\hline B1 & M16586.1 & GTTCTTCAGCACTACGCACTCA- & AAAACCT-ATAAGGTCATGC \\
\hline Тo/1989/20.1 & Z75876.1 & АСTCT-CAGCACTACGCACTCAT & AAAACCT-ATAAGGTCATGC \\
\hline To/1991/2.2 & Z75882.1 & АСТCT-CAGCACTACGCACTCAT & AAAACCT-ATAAGGTCATGC \\
\hline Pratia satRNA & consensus & АСCCT-CAGCACTACGCACTCAT & AAGACCTACACAGGTTATGC \\
\hline
\end{tabular}

Red font indicates positions of nt sequence variation in the CMV-Pratia satRNA nt sequence compared to the others.

A

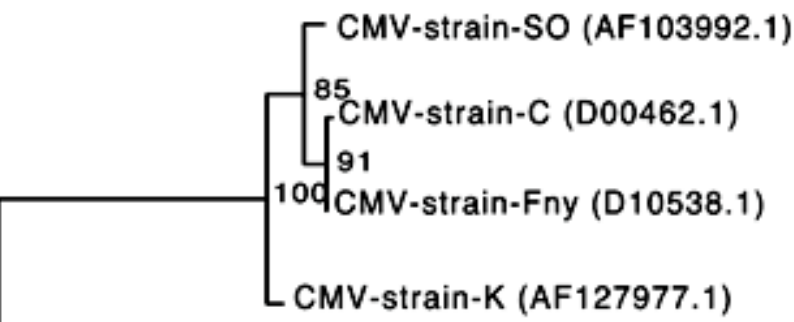

98

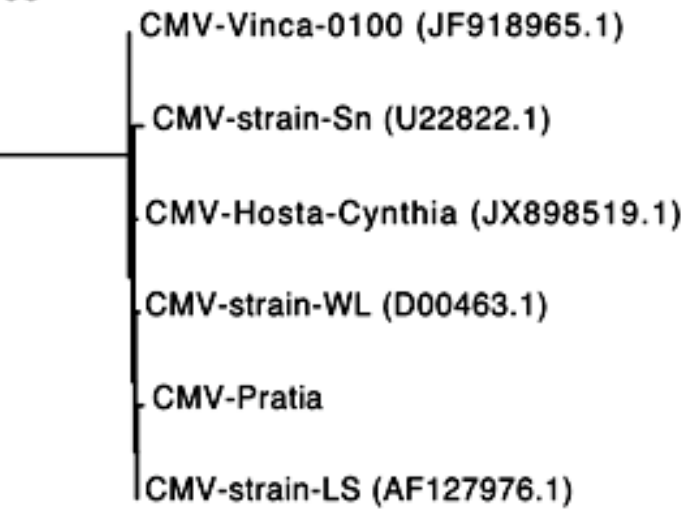

PSV-ER (U15730.1)

0.2 nucleotide substitutions/site 


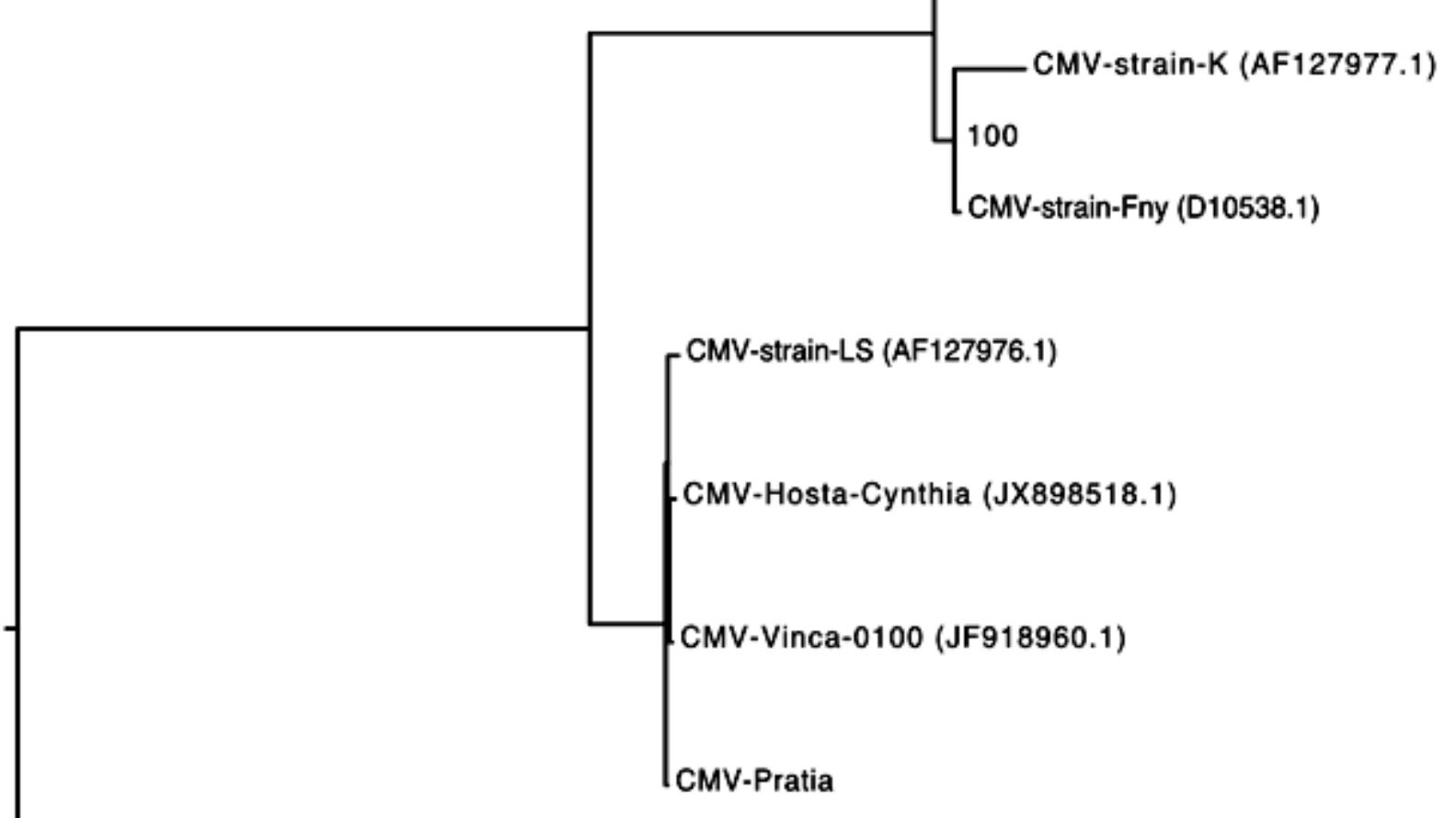

0.1 nucleotide substitutions/site 


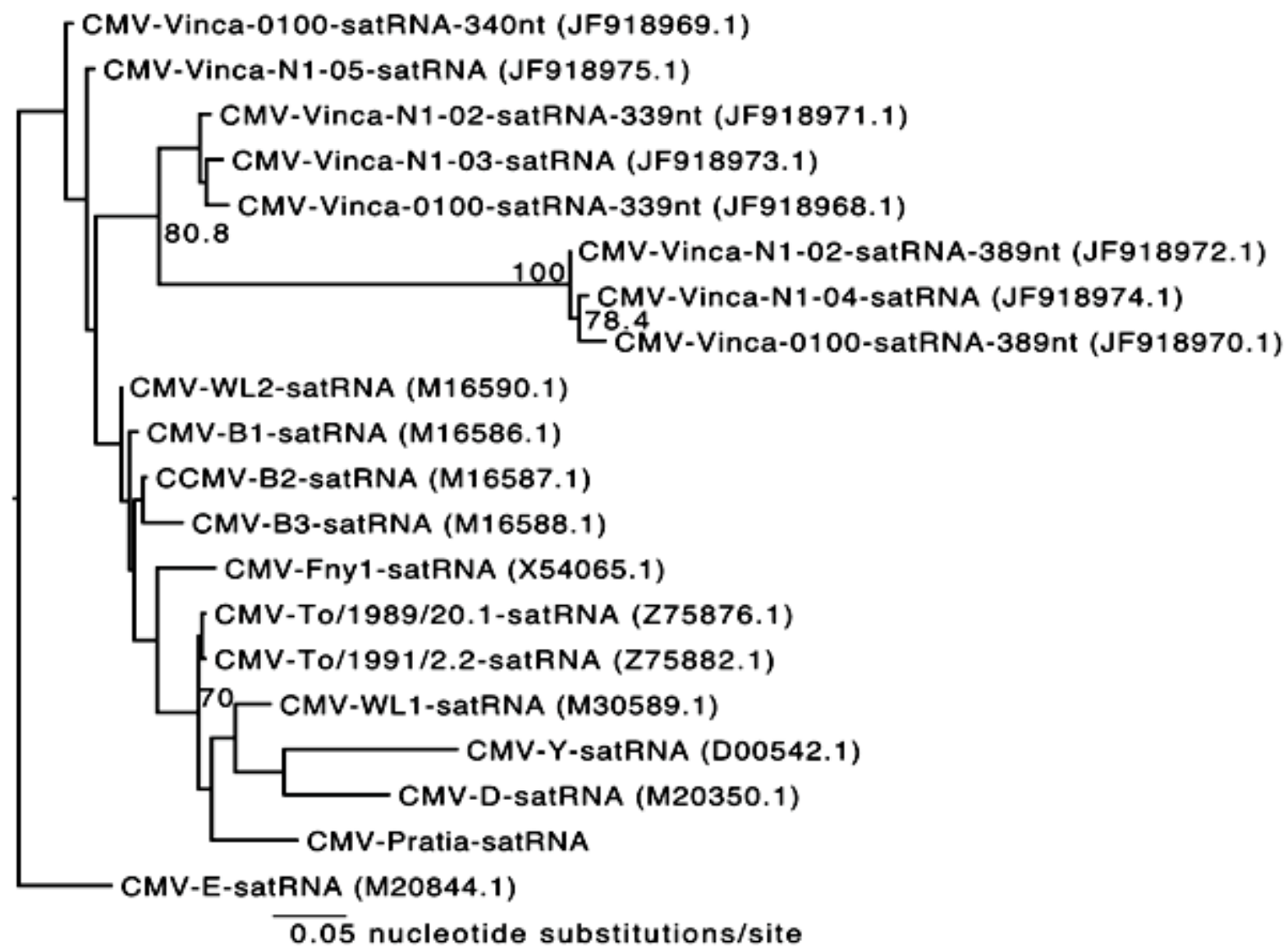

Fig. 2 (above and preceding pages). Rooted phylograms of maximum-likelihood phylogenetic analysis of CMV-Pratia capsid protein ORF $(\mathbf{A})$, movement protein ORF (B), and satRNA nt sequence (C) compared to CMV subgroup I and II strains/isolates and previously characterized satRNAs. 1000 bootstrap replicates were performed and bootstrap values $\geq 70 \%$ are shown on the branches. Peanut stunt virus (PSV) ER strain was used as the outgroup for the CP and MP trees. E-satRNA was used as the outgroup for the satRNA tree. Accession numbers are shown in parentheses.

To our knowledge, the results presented here represent the first confirmed report of CMV infecting Pratia pedunculata. Further, the CMV strain belongs to serological subgroup II, is closely related to CMV-LS, and harbors a $339 \mathrm{nt}$ satRNA that appears to be an undescribed variant with chlorosis and necrosis domains that do not resemble other described satRNAs. Satellite RNAs are known to cause varying disease states when associated with different CMV helper strains and host combinations. It is significant that we detected a satRNA directly from a tissue sample from an established landscape planting of Pratia pedunculata. SatRNAs are more frequently found associated with CMV under experimental conditions but less commonly in agricultural or natural settings (5) and this satRNA is different from any of the sequences in GenBank, including the three classes of satRNA we recently reported from Vinca minor (2). These findings support the notion that ornamental hosts are serving as reservoirs for CMV and in some cases satRNA. What effects, if any, the CMV isolate and satRNA from $P$. pedunculata have on other hosts remains to be explored. Herbaceous ornamental growers and home gardeners should be aware of Blue Star Creeper as a potential source of CMV and its associated satRNA.

\section{Literature Cited}

1. Fisher, J. R. 2013. Identification of a Cucumber mosaic virus subgroup II strain associated with virus-like symptoms on Hosta in Ohio. Online. Plant Health Progress doi:10.1094/PHP-2013-123-01-BR.

2. Fisher, J. R. 2012. Identification of three distinct classes of satellite RNAs associated with two Cucumber mosaic virus serotypes from the ornamental groundcover Vinca minor. Online. Plant Health Progress doi:10.1094/PHP-2012-0412-01-RS. 
3. King, A. M. Q., Adams, M. J., Carstens, E. B., and Lefkowitz, E. J. 2012. Bromoviridae. Pages 965-976 in: Virus Taxonomy, Ninth Report of the International Committee on Taxonomy of Viruses. Elsevier Academic Press, Waltham, MA.

4. Kurath, G., and Palukaitis, P. 1989. Satellite RNAs of cucumber mosaic virus: Recombinants constructed in Vitro reveal independent functional domains for chlorosis and necrosis in tomato. Mol. Plant-Microbe Interact. 2:91-96.

5. Simon, A. E., Roossinck, M. J., and Havelda, Z. 2004. Plant virus satellite and defective interfering RNAs: New paradigms for a new century. Annu. Rev. Phytopathol. 42:415-437.

6. Sleat, D. E., and Palukaitis, P. 1992. A single nucleotide change within a plant virus satellite RNA alters the host specificity of disease induction. Plant J. 2:43-49.

7. Zhang, L., Kim, C. H., and Palukaitis, P. 1994. The chlorosis-induction domain of the satellite RNA of cucumber mosaic virus: Identifying sequences that affect accumulation and the degree of chlorosis. Mol. Plant-Microbe Interact. 7:208-213. 